\title{
Исследования поперечного среза и фотолюминесценции слоя GaAs, выращенного на подложке $\mathrm{Si} / \mathrm{Al}_{2} \mathrm{O}_{3}$
}

\author{
(C) А.А. Сушков, Д.А. Павлов, В.Г. Шенгуров, С.А. Денисов, В.Ю. Чалков, Н.В. Байдусь, \\ А.В. Рыков, Р.Н. Крюков
}

Нижегородский государственный университет им. Н.И. Лобачевского, 603950 Нижний Новгород, Россия

E-mail: sushkovartem@gmail.com

Поступила в Редакцию 24 апреля 2019 г.

В окончательной редакции 29 апреля 2019 г.

Принята к публикации 29 апреля 2019 г.

Сформирована и исследована GaAs/AlAs/GaAs/AlAs/Ge-гетероструктура, выращенная на подложке $\mathrm{Si} / \mathrm{Al}_{2} \mathrm{O}_{3}(1 \overline{1} 02)$. Буферный слой $\mathrm{Ge}$ получен методом „горячей проволоки“, а $\mathrm{A}^{\mathrm{III}} \mathrm{B}^{\mathrm{V}}$ слои с помощью газофазной эпитаксии из металлоорганических соединений. Для определения оптического качества $\mathrm{A}^{\mathrm{III}} \mathrm{B}^{\mathrm{V}}$ слоев использована спектроскопия фотолюминесценции. Структурные исследования проведены с помощью высокоразрешающей просвечивающей электронной микроскопии. Элементный состав определен методом рентгеновской энергодисперсионной спектроскопии. В данной работе была показана возможность роста монокристаллического слоя $\mathrm{GaAs}$ на подложке $\mathrm{Si} / \mathrm{Al}_{2} \mathrm{O}_{3}$ через $\mathrm{AlAs} / \mathrm{GaAs} / \mathrm{AlAs} / \mathrm{Ge}$-буферные слои.

Ключевые слова: гетероэпитаксия, просвечивающая электронная микроскопия, подложка сапфира, слой $\mathrm{GaAs}$, спектры фотолюминесценции.

DOI: 10.21883/FTP.2019.09.48137.20

\section{1. Введение}

В электронных системах управления ядерной энергетикой, в авиакосмической и военной промышленностях в качестве основы для интегральных микросхем (ИМС) используются радиационно стойкие подложки. Кремнийна-сапфире (КНС) и кремний-на-изоляторе (КНИ) являются широко известными реализациями данных структур. Одна из актуальных задач современности - увеличение быстродействия ИМС на радиационно стойких подложках. Способ решить - разработать новые оптические межсоединения [1]. Подход заключается в создании гибридных гетеролазеров $\mathrm{A}^{\mathrm{III}} \mathrm{B}^{\mathrm{V}}$, в которых светоизлучающие полупроводники будут выращены на радиационно стойких подложках. Особенностью подложек КНС и КНИ является наличие верхнего слоя $\mathrm{Si}$. Принимая во внимание, что рост полупроводников группы $\mathrm{A}^{\mathrm{III}} \mathrm{B}^{\mathrm{V}}$ на точно ориентированных подложках $\mathrm{Si}(001)$ с использованием буферных слоев [2] хорошо изучен, представляется логичным перенести технологию на КНС и КНИ подложки.

На данный момент существуют работы по росту $\mathrm{A}^{\mathrm{III}} \mathrm{B}^{\mathrm{V}}$ непосредственно на КНИ без использования буферных слоев, но такие структуры характеризуются высокой плотностью прорастающих дислокаций $[3,4]$. $\mathrm{B}$ структурах КНС больший объем занимает $\mathrm{Al}_{2} \mathrm{O}_{3}$, который имеет ряд преимуществ перед подложкой $\mathrm{Si}$, являющийся основным материалом КНИ. К ним относятся высокие диэлектрические свойства, химическая инертность, прочность, прозрачность в широком спектральном диапазоне от 0.3 до 7 мкм и т.д. На сапфире развита технология роста нитридов $\operatorname{In}_{x} \mathrm{Ga}_{1-x} \mathrm{~N}$, у которых в зависимости от доли $\operatorname{In}(x)$ ширина запрещенной зоны варьируется в широком спектральном диапазоне от 0.7 до 3.4 эВ. Однако из-за различия параметров решеток $\mathrm{GaN}$ и $\mathrm{Al}_{2} \mathrm{O}_{3}(16 \%)$, а также коэффициента термического расширения (34\%) слои имеют высокую плотность дефектов. Для ее уменьшения используют различные методы [5], которые усложняют и делают технологию более дорогостоящей. В качестве альтернативы для инфракрасной области спектра предлагается использовать напряженные InGaAs/GaAs-квантовые ямы (КЯ) [6] на буферных слоях GaAs/AlAs/GaAs/AlAs/Ge и подложке $\mathrm{Si} / \mathrm{Al}_{2} \mathrm{O}_{3}$. Для того чтобы получать высокого оптического качества InGaAs/GaAs КЯ, необходимо сначала отработать технологию роста $\mathrm{GaAs}$ на подложке $\mathrm{Si} / \mathrm{Al}_{2} \mathrm{O}_{3}$ с минимальными значениями плотности прорастающих дефектов и шероховатости поверхности.

В настоящей работе представлены результаты исследования оптических и структурных свойств слоя GaAs, выращенного на системе буферных слоев $\mathrm{AlAs} / \mathrm{GaAs} / \mathrm{AlAs} / \mathrm{Ge}$ и подложке $\mathrm{Si} / \mathrm{Al}_{2} \mathrm{O}_{3}(1 \overline{1} 02)$.

\section{2. Методика эксперимента}

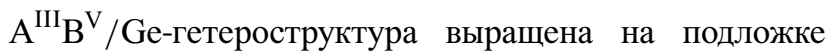
$\mathrm{Si} / \mathrm{Al}_{2} \mathrm{O}_{3}(1 \overline{1} 02)$ в две стадии. До начала роста проводились стандартное RCA травление и термическая очистка подложки при $900^{\circ} \mathrm{C}$. На первой стадии выращивали слой $\mathrm{Si}$ толщиной 200 нм методом молекулярно-пучковой эпитаксии при температуре роста $800^{\circ} \mathrm{C}$ в течение 20 мин, а затем слой Ge толщиной 1.7 мкм - методом газофазного осаждения с разложением моногермана $\left(\mathrm{GeH}_{4}\right)$ на „горячей проволоке“ при температуре роста $\sim 350^{\circ} \mathrm{C}[7]$. На второй стадии $\mathrm{A}^{\mathrm{III}} \mathrm{B}^{\mathrm{V}}$ слои были выра- 
щены методом МОС-гидридной эпитаксии на установке AIX 200RF при давлении 50 мбар. Перед этим был проведен отжиг подложки при температуре $700^{\circ} \mathrm{C}$ в атмосфере $\mathrm{H}_{2}$. Рост системы слоев AlAs/GaAs/AlAs c толщинами 10/50/10 нм соответственно был проведен при температуре $700^{\circ} \mathrm{C}$. После этого выращен нелегированный слой GaAs толщиной 1.2 мкм при скорости роста $1 \mathrm{Hм} / \mathrm{c}$ и при той же температуре. В качестве прекурсоров выступали триметилгаллия $\mathrm{Ga}\left(\mathrm{CH}_{3}\right)_{3}$, триметилалюминия $\mathrm{Al}\left(\mathrm{CH}_{3}\right)_{3}$ и арсин $\mathrm{AsH}_{3}$. Плотность дислокаций в верхнем слое $\mathrm{GaAs}$, выявленных с использованием селективного травления, оценивалась методом подсчета ямок травления (EPD - etch pit density) на изображении, полученном с помощью атомно-силовой микроскопии (АСM). Оптическое качество эпитаксиальных слоев исследовано с помощью спектроскопии фотолюминесценции (ФЛ). Структурные и аналитические исследования проведены с помощью высокоразрешающей просвечивающей электронной микроскопии (ВРПЭМ) и рентгеновской энергодисперсионной спектроскопии (ЭДС) соответственно.

\section{3. Результаты и обсуждение}

Измерения спектров фотолюминесценции при комнатной температуре проведены на установке Nanometrics RPM-2000, которая позволяет сканировать образец c разрешением меньше $0.1 \mathrm{Mм}$. В качестве источника возбуждения для получения спектров и карт ФЛ использовался $\mathrm{Nd}$ : YAG-лазер с длиной волны 532 нм и оптической плотностью мощности 341.7 Вт/см ${ }^{2}$. Спектр ФЛ с максимумом в $862.5 \mathrm{Hм}$, соответствующий $\mathrm{GaAs}$, показан на рис. 1. Карты ФЛ демонстрируют однородность выращенного верхнего слоя GaAs по площади подложки: среднее значение максимумов длин волн составляет $(862.3 \pm 0.7) \mathrm{HM,} \mathrm{а} \mathrm{ширины} \mathrm{пика} \mathrm{на} \mathrm{полу-}$ высоте $(\mathrm{FWHM})-(26.7 \pm 1.1)$ нм. Сдвиг максимума спектра ФЛ в направление коротких длин волн является

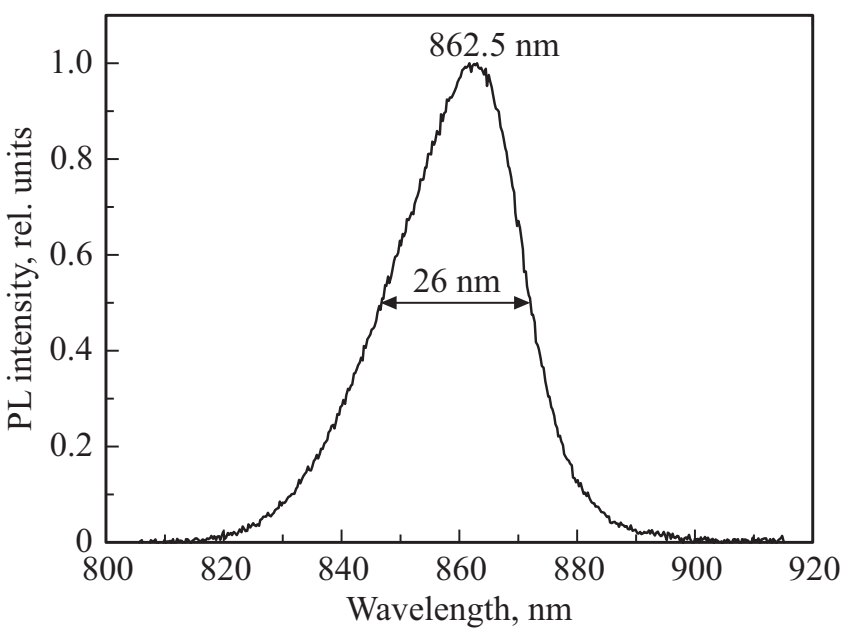

Рис. 1. Спектр ФЛ $\mathrm{A}^{\mathrm{III}} \mathrm{B}^{\mathrm{V}} / \mathrm{Ge} / \mathrm{Si} / \mathrm{Al}_{2} \mathrm{O}_{3}(1 \overline{1} 02)$ структуры.

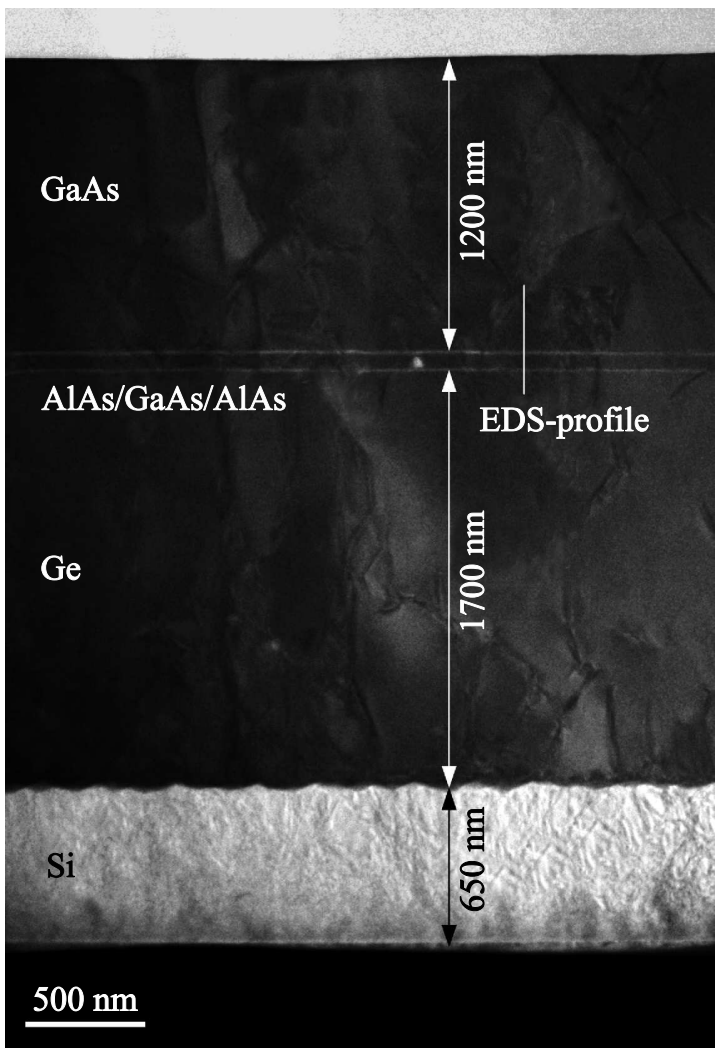

Рис. 2. Обзорное ПЭМ-изображение структуры, включающее область с ЭДС-профилем.

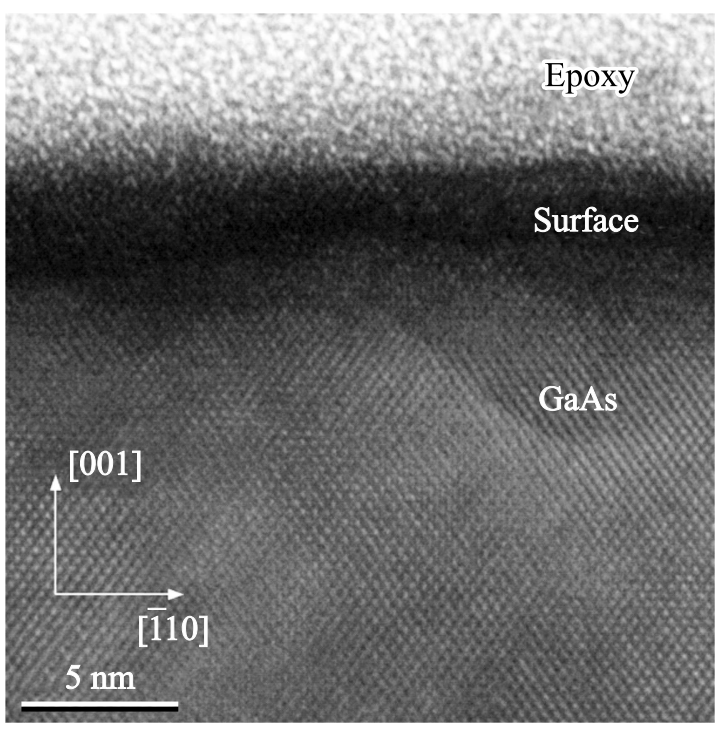

Рис. 3. ВРПЭМ-изображение поперечного среза поверхности слоя $\mathrm{GaAs}$, выращенного на подложке $\mathrm{Si} / \mathrm{Al}_{2} \mathrm{O}_{3}(1 \overline{1} 02)$.

типичным для GaAs, выращенного на Ge и на подложках $\mathrm{Ge} / \mathrm{Si}[8]$.

Препарирование поперечного среза структуры GaAs/ $\mathrm{AlAs} / \mathrm{GaAs} / \mathrm{AlAs} / \mathrm{Ge} / \mathrm{Si} / \mathrm{Al}_{2} \mathrm{O}_{3}(1 \overline{1} 02)$ проводилось с использованием Gatan 691 PIPS (Precision Ion Polishing System). Исследования ВРПЭМ и ЭДС выполнены на 
электронном микроскопе JEOL JEM-2100F (200 кB) с энергодисперсионным детектором Oxford Instruments X-MАХ. Серия ПЭМ-изображений поперечного среза структуры была получена в режиме фазового контраста. Обзорное ПЭМ-исследование представлено на рис. 2. ВРПЭМ-исследования показали, что слой GaAs имеет монокристаллическую структуру (рис. 3). Дифракционная картина (не показано) демонстрирует характерные для GaAs со структурным типом сфалерит рефлексы. На рис. 4 видно, что дефекты, образующиеся вблизи гетерограницы $\mathrm{AlAs} / \mathrm{Ge}$ и распространяющиеся к поверхности, частично запираются между прослойками AlAs. ЭДС-исследования подтверждают, что слой AlAs предотвращает взаимную диффузию атомов $\mathrm{Ge}, \mathrm{Ga}$ и As между GaAs и Ge (рис. 5), что согласуется с результатами в других работах $[2,9]$.

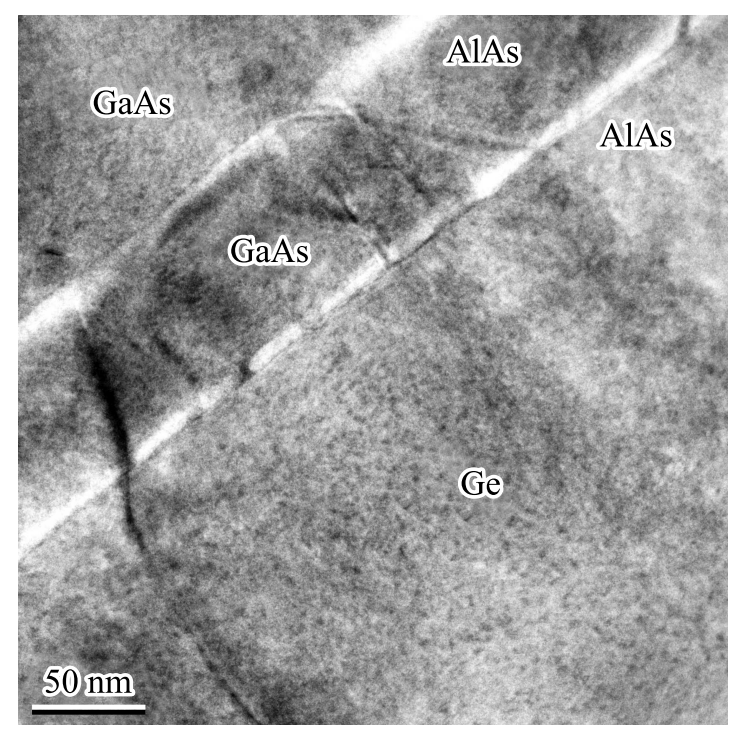

Рис. 4. ПЭМ-изображение поперечного среза GaAs/AlAs/

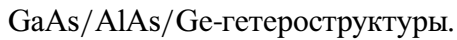

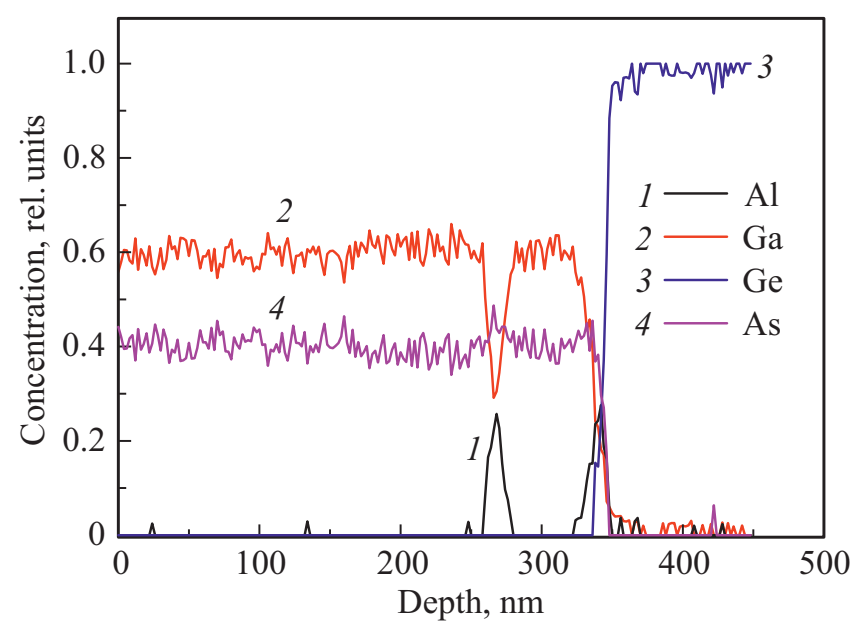

Рис. 5. ЭДС-профиль распределения состава в слоях $\mathrm{GaAs} / \mathrm{AlAs} / \mathrm{GaAs} / \mathrm{AlAs} / \mathrm{Ge}$.

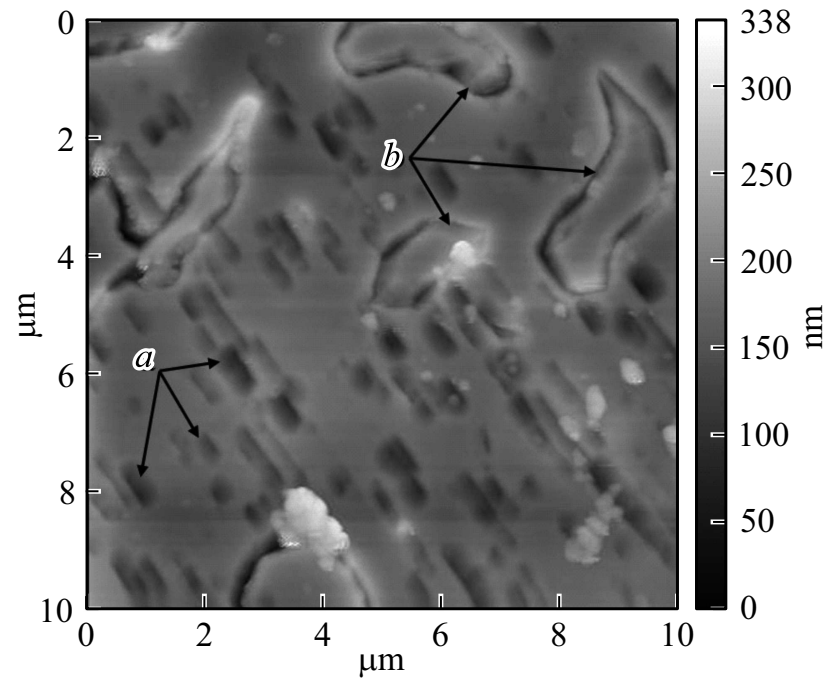

Рис. 6. АСМ-изображение поверхности слоя GaAs после проведения селективного травления. ( $a$ - ямы травления, $b-$ антифазные границы).

АСМ-изображение (рис. 6) было получено на атомносиловом микроскопе Solver Pro в полуконтактном режиме, с использованием зондов НА NC (НT-МДТ, г. Зеленоград, Россия). Значение количества ямок травления равно $9 \cdot 10^{7} \mathrm{~cm}^{-2}$. Оно сопоставимо с результатами для образцов, выращенных на $\mathrm{Si}$ подложках [10]. Также стоит отметить, что травитель еще больше проявил антифазные границы (АФГ) — замкнутые фигуры неправильной формы. Наличие АФГ объясняется ростом бинарного полупроводника с полярной связью на неотклоненной поверхности неполярного кристалла с ориентацией типа (001) [11]. В данном образце неполярным кристаллом является кремний. Ha R-срезе сапфира $\left(\mathrm{Al}_{2} \mathrm{O}_{3}(1 \overline{1} 02)\right)$ он имеет ориентацию типа (001).

\section{4. Заключение}

Таким образом, был выращен и исследован слой GaAs на подложке $\mathrm{Si} / \mathrm{Al}_{2} \mathrm{O}_{3}(1 \overline{1} 02)$ с буферными слоями $\mathrm{AlAs} / \mathrm{GaAs} / \mathrm{AlAs} / \mathrm{Ge}$. Результаты данной работы указывают на возможность роста напряженных InGaAs/GaAs-квантовых ям на подложке сапфира с использованием буферных слоев для создания светоизлучающих структур на радиационно стойких подложках. Это мотивирует на дальнейшие исследования с целью получения слоя GaAs высокого структурного качества на буферных слоях и подложке $\mathrm{Si} / \mathrm{Al}_{2} \mathrm{O}_{3}$.

\section{Финансирование работы}

Работа выполнена при финансовой поддержке Российского фонда фундаментальных исследований (проект № 18-32-00636 - МОС-гидридная эпитаксия и 
измерения ФЛ) и Министерства образования и науки Российской Федерации (проект № 16.7443.2017/БЧ).

\section{Конфликт интересов}

Авторы заявляют, что у них нет конфликта интересов.

\section{Список литературы}

[1] T. Creazzo, E. Marchena, S.B. Krasulick, P.K.L. Yu, D. Van Orden, J.Y. Spann, C.C. Blivin, L. He, H. Cai, J.M. Dallesasse, R.J. Stone, A. Mizzahi. Opt. Express, 21 (23), 28048 (2013).

[2] N. Baidus, V. Aleshkin, A. Dubinov, K. Kudryavtsev, S. Nekorkin, A. Novikov, D. Pavlov, A. Rykov, A. Sushkov, M. Shaleev, P. Yunin, D. Yurasov, Z. Krasilnik. Crystals, 8 (8), 311 (2018)

[3] M.L. Seaford, D.H. Tomich, K.G. Eyink, L. Grazulis, K. Mahalingham, Z. Yang, W.I. Wang. J. Electron. Mater., 29 (7), 906 (2000).

[4] N.H. Karam, V. Haven, S.M. Vernon, F. Namavar, N. El-Masry, N. Haegel, M.M. Al-Jassim. Mater. Res. Soc. Symp. Proc., 198, 247 (1990).

[5] H. Lin, R. Lin, J. Chyi, C.M. Lee. IEEE Photon. Techn. Lett., 20 (19), 1621 (2008).

[6] V.Ya. Aleshkin, N.V. Baidus, A.A. Dubinov, A.G. Fefelov, Z.F. Krasilnik, K.E. Kudryavtsev, S.M. Nekorkin, A.V. Novikov, D.A. Pavlov, I.V. Samartsev, E.V. Skorokhodov, M.V. Shaleev, A.A. Sushkov, A.N. Yablonskiy, P.A. Yunin, D.V. Yurasov. Appl. Phys. Lett., 109, 061111 (2016).

[7] V.G. Shengurov, S.A. Denisov, V.Yu. Chalkov, Yu.N. Buzynin, M.N. Drozdov, A.N. Buzynin, P.A. Yunin. Techn. Phys. Lett., 41 (1), 36 (2015).

[8] A.V. Rykov, M.V. Dorokhin, P.S. Vergeles, N.V. Baidus, V.A. Kovalskiy, E.B. Yakimov, O.A. Soltanovich. J. Phys.: Conf. Ser., 993, 012014 (2018).

[9] C.K. Chia, J.R. Dong, D.Z. Chi, A. Sridhara, A.S.W. Wong, M. Suryana, G.K. Dalapati, S.J. Chua, S.J. Lee. Appl. Phys. Lett., 92, 141905 (2008).

[10] A.V. Rykov, M.V. Dorokhin, P.S. Vergeles, V.A. Kovalskiy, E.B. Yakimov, M.V. Ved, N.V. Baidus, A.V. Zdoroveyshchev, V.G. Shengurov, S.A. Denisov. J. Phys.: Conf. Ser., 1124, 022037 (2018).

[11] Yu.B. Bolkhovityanov, O.P. Pchelyakov. Physics-Uspekhi, 51 (5), 437 (2008).

Редактор Г.А. Оганесян

\section{Cross section TEM} and photoluminescence investigation of GaAs layer grown on silicon-on-sapphire

\author{
A.A. Sushkov, D.A. Pavlov, V.G. Shengurov, \\ S.A. Denisov, V.Yu. Chalkov, N.V. Baidus, \\ A.V. Rykov, R.N. Kryukov
}

Lobachevsky State University of Nizhny Novgorog, 603950 Nizhny Novgorod, Russia

\begin{abstract}
AlAs} / \mathrm{GaAs} / \mathrm{AlAs} / \mathrm{Ge}$ heterostructure and GaAs film grown on $\mathrm{Si} / \mathrm{Al}_{2} \mathrm{O}_{3}$ substrate has been fabricated and studied. Ge buffer on $\mathrm{Si} / \mathrm{Al}_{2} \mathrm{O}_{3}$ substrate was produced via a one step hot wire chemical vapor deposition process at $350^{\circ} \mathrm{C} . \mathrm{A}^{\mathrm{III}} \mathrm{B}^{\mathrm{V}}$ films were grown via low pressure MOCVD. Photoluminescence spectroscopy was used to define optical quality of $\mathrm{A}^{\mathrm{III}} \mathrm{B}^{\mathrm{V}}$ films. Structural properties were investigated by high-resolution transmission electron microscopy. Distribution of elements in the heterostructure was carried out by energy-dispersive $X$-ray spectroscopy. The possibility of growth of monocrystallic GaAs on silicon-on-sapphire substrate has been shown through growth of $\mathrm{AlAs} / \mathrm{GaAs} / \mathrm{AlAs} / \mathrm{Ge}$ buffer layers.
\end{abstract}

